\title{
Why Are Firms Rigid? A General Framework and Empirical Tests*
}

\author{
Rui J.P. de Figueiredo Jr. \\ Haas School of Business, University of California Berkeley \\ rui@haas.berkeley.edu \\ Evan Rawley \\ Columbia Business School \\ erawley@columbia.edu \\ Christopher I. Rider \\ McDonough School of Business, Georgetown University \\ chris.rider@georgetown.edu
}

\begin{abstract}
Many firms resist making major strategic changes, but the source of such rigidity varies across settings. This paper develops and tests a general framework for identifying the key basis of organizational rigidity in a wide range of empirical contexts. We motivate mechanism-specific predictions for rigidity in old versus young firms, based on ex ante and ex post firm performance, and then test the competing hypotheses in the context of hedge fund product diversification. We first establish the key scope condition for our framework - a negative relationship between firm age and the diversification rate - and then show that younger firms outperform older firms both prior to and after the launch of a new fund. The results suggest that age-based rigidity in hedge funds is more attributable to internal political frictions with respect to project selection than to constraints associated with exchange partners or implementation costs. We conclude by discussing how our framework may be applied in other settings.
\end{abstract}

\section{Introduction}

Why do established firms resist making major strategic changes? Scholars have long noted that rigidity limits firm growth, innovation, and performance (Leonard-Barton, 1992). Yet, rigidity is an ambiguous explanation for a firm's tendency to maintain the status quo, in part because rigidity arises from an unobserved organizational process. Consequently, identifying the primary constraint on adaptation remains challenging despite a long line of thought-provoking work on the impediments to organizational change (e.g., Cyert and March, 1963; Hannan and Freeman, 1984; Christensen and Bower, 1996). This manuscript addresses this gap in the literature, by developing a general framework for identifying the

\footnotetext{
${ }^{*}$ We thank Nick Argyres, Matthew Bidwell, Olivier Chatain, Emilie Feldman, Rahul Kapoor, Felipe Monteiro, Jesper Sørensen, and seminar participants at Seoul National University, as well as participants at the 2013 Atlanta Competitive Advantage Conference, the $13^{\text {th }}$ Meeting of Organizational Ecologists and the $2^{\text {nd }}$ NYU Economics of Strategy Conference for comments on earlier drafts of this work.
} 
main source of organizational rigidity in a wide range of settings, and applies the framework in the context of hedge fund product diversification to understand why older firms make major strategic changes less often than younger ones.

Our investigation of rigidity systematically reviews three prominent accounts in the diverse literatures that address the tendency of firms to preserve the status quo. Generally, firms may resist change because of the difficulties of securing exchange partner support (e.g., investors, customers, suppliers), of negotiating internal politics, or of overcoming deficient change capabilities. A common thread in prior work is the idea that each of these three sources of rigidity-exchange partner reservations, political frictions, and implementation capabilities - increase with firm age.

Extending these ideas, we develop a conceptual framework that derives unique performance patterns for each potential source of organizational rigidity, conditional on evidence of rigidity with respect to a particular type of strategic change (e.g., age-based rigidity in the context of diversification). After formally deriving these distinctive effects we apply the framework in the context of hedge fund product diversification, demonstrating how the application of our framework enables one to diagnose the primary rigidity-producing mechanism in a particular setting. ${ }^{1}$

Our framework establishes the key scope condition for its application: a negative correlation between a firm covariate (e.g., age) and the rate of change (e.g., diversification). The framework also formally incorporates both external and internal mechanisms underlying firm rigidity. For example, as we elaborate upon later, exchange partners may treat the firm's ex ante performance as evidence of a focal firm's capabilities and, wary that performance will suffer if legacy routines are altered, support diversification only if ex ante performance is sufficiently high (i.e., the firm is believed to be highly capable). Accordingly, if exchange partners are more constraining for older firms than for younger ones, then old diversifiers should exhibit higher ex ante performance than young diversifiers. Internally, if

\footnotetext{
${ }^{1}$ Empirically, we consider age-based determinants of rigidity in the context of product diversification. But, as we discuss later in the paper, our framework may be applied to investigate other firm-level correlates of rigidity (e.g., size) and to other major strategic changes (e.g., information technology adoption)
} 
organizational insiders prioritize their interests over firm interests and, therefore, require political compromises to support change, and older firms are more politicized than younger ones with respect to project selection, then older diversifiers will exhibit lower ex post performance following diversification than younger firms. Conversely, older diversifiers will exhibit higher ex post performance following diversification than younger firms if the costs of implementing change are increasing with age.

We test these competing predictions by analyzing data from 2,814 hedge fund firms between 1994 and 2005. Empirically, we focus on changes to firms' horizontal boundaries triggered by major new product launches (“diversification events"). To satisfy our key scope condition, we first document a negative relationship between organizational age and the diversification rate, a prerequisite to testing our mechanism-specific, rigidity hypotheses. We then distinguish between external and internal constraints on strategic change by focusing on ex ante performance (i.e., performance prior to diversifying). We find that older diversifying firms exhibit lower ex ante performance than younger diversifying firms, implying that extremal performance standards are lower for older diversifying firms than for younger diversifiers. Thus, we infer that, in this setting, the primary constraint on strategic change is internal in nature - either political or operational. To further distinguish between political frictions and implementation costs, we focus on ex post performance, where we find that older diversifying firms exhibit lower ex post performance than younger ones. Thus, the evidence is consistent with the idea that older hedge funds are more constrained by political frictions with respect to project selection than younger ones.

This study offers three primary contributions. First, the idea that organizational politics stifles change dates at least to Cyert and March (1963), but the possibility that organizational aging produces rigidity by increasingly politicizing change efforts has received limited empirical attention (c.f., Christensen and Bower, 1996; Gavetti, et. al., 2007). Given that hedge funds are thought to be less bureaucratic than conventional firms, the evidence suggests that political frictions play a larger role in inhibiting change than is commonly recognized. Second, we demonstrate that internal politics may be sufficient to substantially reduce product introduction rates in a highly innovative industry. To our knowledge, the political element of rigidity has not yet been applied to the study of firm scope despite sustained scholarly 
interest in diversification (e.g., Teece, 1982; Silverman, 1999; Zhou, 2011). Third, our study offers a general framework for adjudicating multiple accounts of organizational rigidity; most prior research considers sources of rigidity in isolation (e.g., Miller and Chen, 1994). Subject to a few basic assumptions and a change rate that varies systematically with a key organizational covariate (e.g., age), our framework enables scholars to identify, based on observable performance patterns, which of several mechanisms primarily constrain strategic change in a wide range of settings.

\section{Theoretical Development}

Organizational innovation rates (e.g., Sørensen and Stuart, 2000), growth (e.g., Evans 1987), size (e.g., Dunne, et. al. 1989), and survival (e.g., Dunne, et. al. 1988) all vary systematically with organizational age. Prior work demonstrates that age influences organizations both positively and negatively, but the general consensus is that older firms are less likely to change than younger firms. The theory of structural inertia, for example, emphasizes how selection pressures favor organizations that maintain their core features over time (Hannan and Freeman, 1984). Although organizations develop capabilities as they age (Jovanovic 1982), established routines are repeatedly exploited (Nelson and Winter, 1982; March, 1991). Thus, if firms prefer established routines over novel ones then, ceteris paribus, older firms will be less likely to make major organizational changes. For example, substantially expanding horizontal scope alters "the kinds of clients (or customers) to which the organization orients its production and the ways in which it attracts resources from the environment" (Hannan and Freeman, 1984: 1560). Indeed, the literature on age and change highlights several non-exclusive mechanisms that might produce a negative relationship between age and strategic change. To understand rigidity, we disentangle these mechanisms.

Once an organization overcomes the liability of newness (Stinchcombe, 1965), it institutionalizes goals, standardizes activities, and hones capabilities so that, over time, reliable routines evolve (Nelson and Winter, 1982). Strong incentives to continue exploiting established routines instead of developing new ones renders strategic change risky because change compromises the survival advantages of age (March, 1991; Desai, 2008). 
Changes to core organizational features, such as a firm's product portfolio, are especially risky not only because the core routines must be modified, but also because the basis for market evaluations is altered (Zuckerman, 1999). Organizations, therefore, tend to preserve the status quo, and older organizations change less often than younger ones (e.g., Amburgey, et al., 1993). Building on this body of work, we explicitly evaluate the benefits and costs of implementing change to understand how aging influences one important strategic change: diversification, or the horizontal expansion of an established firm's scope via the introduction of new product offerings (Teece, 1982).

Diversification is intrinsically interesting because of its implications for growth, performance, and market evaluation. Recent work characterizes diversification as being motivated by expected economies of scope borne of cost reductions or revenue enhancements (Campa and Kedia 2002). But, diversification also creates incentive conflicts (Pierce, 2012), taxes organizations' information processing capabilities (Zhou, 2011), and distracts managers from their responsibilities (Schoar, 2002), arguably contributing to a “diversification discount" (Lang and Stulz 1994). Aside from the question of whether diversification creates or destroys value, the decision to diversify is an important organizational problem to study, because it is illustrative of the challenges organizations face in evaluating major strategic changes more generally.

Our conceptual and empirical focus is on major diversification events. Accordingly, we treat the launch of a fundamentally new product or service offering as a major organizational change and treat product line extensions as minor changes. Below, we consider multiple mechanisms that could produce a negative relationship between age and diversification rates and then consider each mechanism's implications for firm performance.

\subsection{Firm age and the rate of change.}

Extant research identifies three primary constraints on strategic change: exchange partner reservations, internal political frictions, and implementation capabilities. Below, we briefly discuss each rigidity source in turn to highlight common themes as well as key points of distinction. 
The first type of constraint on strategic change is the necessity of persuading exchange partners to support the change. With age, firms become embedded in exchange relationships with customers, suppliers, investors, and others that associate the firm with its established offerings (Argyres and Liebeskind, 1999). New offerings often prompt partner concerns about the firm's commitment to those who produce and consume the firm's legacy products or services (e.g., Phillips, et. al., 2013). Firms must assuage these concerns with a compelling change rationale in order to secure the resources necessary for horizontal scope expansion. To the extent that exchange partner reservations grow stronger with relational time (e.g., Uzzi, 1996), these external constraints on change increase with age.

The second type of constraint on strategic change is the politicization of internal decision making. Bureaucracy develops over time, reducing uncertainty and stabilizing the organizational power distribution (Barron, et al., 1994). Bureaucracy usually serves the interests of the firm's most powerful employees, enabling them to allocate resources disproportionately to efforts that preserve their power (Pfeffer, 1981). Consequently, change is difficult to negotiate between those who support established routines and those who want to develop new ones, because such differences create political frictions that must be resolved before a strategic change is made. By necessitating ever more political bargains, bureaucracy increasingly constrains change as organizations age. In this paper, we focus conceptually and empirically on political frictions that act as a noisy filter on organizational decision-making, producing Type 1 and Type 2 errors - errors of omission and commission-in project selection.

The third type of constraint on strategic change is an internal operational limitation-which we refer to as implementation costs. Structural features of the organization are difficult to change because firms develop routines over time, which are costly to adapt. For example, management might feel that diversification would be beneficial in the absence of internal implementation costs, yet forego a new product or service because of concerns about the costs and time associated with adaptation. Because older firms utilize established routines more heavily than younger ones, implementation costs related to strategic changes should be greater for older firms. Similarly, if the implementation of a new idea requires concessions that are independent of project selection (e.g., promotions, bonuses, etc.) to secure 
internal support for change, then such concessions are considered to be a form of implementation costsnot the noise-inducing political frictions we describe above.

Rigidity may, thus, be borne of three constraints associated with external exchange partner reservations, internal political frictions, and internal implementation costs and capabilities. As each is thought to be increasing in magnitude with age, the key scope condition for our investigation is that, ceteris paribus, the diversification rate is negatively correlated with firm age. While the arguments above imply that this scope condition is commonly satisfied, it will not always be met. Older firms can sometimes leverage their superior resources and capabilities to expand horizontal scope faster than their younger counterparts. But, the purpose of this study is not to investigate the conditions under which our scope condition prevails, but rather, to establish a framework for identifying the key mechanism behind organizational rigidity. Thus, evaluating our scope condition empirically sets the stage for testing our conceptual framework.

\subsection{Age, change, and performance}

All three accounts of rigidity imply that as a firm ages its propensity to initiate major strategic changes declines. Accordingly, simply analyzing diversification rates alone will not reveal the primary factor constraining strategic change. To identify the primary rigidity-producing mechanism, we consider the distinctive implications of each account for firm performance before and after a strategic change.

We elucidate theoretical relationships amongst age, diversification, and performance by developing a simple formalization of the decision to expand horizontal scope based on three broad precepts. First, we assume that firms are motivated to diversify when doing so is expected to enhance profitability. Second, we assume that the distribution of returns to new opportunities (e.g., the arrival of ideas) does not vary with age, ${ }^{2}$ and that opportunities are evaluated by risk-neutral decision-makers within the firm on the basis of their expected returns relative to maintaining the status quo. In general, if the expected returns to

\footnotetext{
${ }^{2}$ Although differential rates of diversification may develop with age, our hypotheses about ex post performance do not depend on the rate of idea generation. We elaborate on the implications of relaxing this assumption in our discussion of the results.
} 
an opportunity exceed a minimum threshold - a hurdle rate-profit-seeking firms implement change; otherwise, the status quo is maintained. Important exceptions are discussed below. Third, we assume that there is asymmetric information about change opportunities between exchange partners and firms. Profit-seeking firms assess new opportunities on the basis of expected future returns from such opportunities (i.e., expected ex post performance). Conversely, exchange partners (e.g., investors) decide whether they will support change based on the focal firm's historical performance (i.e., observed ex ante performance). ${ }^{3}$ From these basic assumptions we generate competing predictions-one for each mechanism - about firm performance before and after diversification events, in firms that exhibit a negative correlation between age and the diversification rate.

\subsubsection{External exchange partner constraints on organizational change and ex ante performance}

Firms are generally obligated to exchange partners who invested in legacy offerings (Argryes and Liebeskind, 1999), and must renew or develop new relationships to introduce new offerings. Thus, diversifying firms must persuade external parties that a new offering will be successful and will not adversely affect the firm's legacy routines.

Old firms may hold certain advantages over young firms (e.g., trust, learning, slack resources), but age may be disadvantageous in the context of strategic change for two reasons. First, because organizational routines calcify with age (Leonard-Barton, 1992), exchange partners will justifiably be concerned that diversification by older firms will compromise established firms' competitive advantage (Rawley, 2010). Second, given that executives feel obligated to inform long-time suppliers of impending changes that may adversely affect their business (Uzzi, 1996), and older organizations tend to maintain commitments to current customers instead of developing products more readily for potential new customers (Christensen and Bower, 1996), exchange partner obligations will generally increase with age.

\footnotetext{
${ }^{3}$ The assumption that external exchange partners only utilize ex ante information makes implicit that firms lack the motivation and/or capacity to communicate the potential of new business lines accurately. In other words, because firms have incentives to manipulate external stakeholder's information and beliefs, external exchange partners will interpret public claims about project profitability as cheap talk.
} 
While external exchange partners are likely skeptical of an established firm's new offerings, they will be more favorable if a diversifying firm has performed well historically, because strong performers have a demonstrated track record of success. Therefore, if external constraints on diversification are the primary driver of organizational rigidity, and the extant theory we describe above is correct, then the hurdle rate for a new product or service (i.e., ex ante performance) should be higher for older than for younger firms. ${ }^{4}$

To demonstrate the age-related implications of this argument for a firm's ex ante performance, consider a simple, reduced-form model applied to an "old" and "young" firm, denoted respectively by $i \in\{o, y\}$. Each maintains a single legacy offering and considers launching a new offering. The legacy offering has a track record of performance $r_{i}$ where track records are distributed according to a normal distribution $f$ with mean $\mu_{r}$ and variance $\sigma_{r}$. Firms are motivated to diversify in pursuit of profits, but must secure exchange partner support in order to do so.

Exchange partners evaluate a firm's proposed change based, in part, on the ex ante performance of its legacy offerings. Thus, exchange partners are more likely to support diversification if the firm's recent performance is sufficiently positive (i.e., above a hurdle rate).

We denote the hurdle rate that exchange partners apply for each firm $h_{i}^{a}$ where $i \in\{o, y\}$ and the superscript $a$ denotes that the hurdle is on the ex ante performance distribution, where the hurdle rate exceeds the mean of the performance distribution. Figure 1 illustrates this idea, where $f(r)$ represents the distribution of track records and $h$ represents the hurdle rate $h$. Firm decisions are straightforward: launch the new product if $r_{i}>h_{i}^{a}$.

If exchange partners apply a higher standard to older firms than to younger ones-implying that investors in older firms are more reticent to allow the firms to deviate from their stated path, then

\footnotetext{
${ }^{4}$ Alternative theories that posit the opposite implication of each age-based mechanism are potentially valid null hypotheses. For example, we propose above that external exchange partner constraints will be stronger for older firms, conditional on older firms diversifying at a lower rate than younger firms. But, of course, under some circumstances external exchange partner constraints may be stronger for younger firms. We explicitly evaluate the prediction of the extant theory against this null hypothesis in our empirical tests.
} 
$h_{o}^{a}>h_{y}^{a}$. This logic motivates a prediction about the relationship between new product introductions and ex ante performance based on age-varying external constraints. For clarity, the indicator variable $d$ denotes a diversification choice, such that $d=1$ if an organization launches a new product and $d=0$ if not. Namely, we can write the average ex ante performance conditional on diversification as:

$$
E\left(r_{i} \mid r_{i}>h_{i}^{a}\right)=\int_{h_{i}^{a}}^{\infty} r_{i} f(r) d r_{f}
$$

Given that the normal distribution is single-peaked and $h_{o}^{a}>h_{y}^{a}$, Equation (1) implies:

$$
E_{o}\left(r_{o} \mid d=1\right)>E_{y}\left(r_{y} \mid d=1\right) .
$$

Equation (2) states that the average ex ante performance conditional on diversifying will be higher for older firms. Figure 2 illustrates the intuition. The average ex ante returns for older firms is the weighted average of performance above the hurdle rate (i.e., the cross-hatched area in Figure 2). Because young firms face lower hurdle rates than old ones, the calculation of the young firm mean includes all of the area occupied by older firms and the additional area between the two hurdle rates $h_{o}^{a}$ and $h_{y}^{a}$. Because this area originates at lower performance values for younger than for older firms, the expectation, conditional on the hurdle rate, is also lower for younger firms, if external constraints limit strategic change. ${ }^{5}$ These arguments motivate our first hypothesis:

Hypothesis 1: If exchange partner reservations are the primary constraint on change, then the ex ante performance of older diversifiers will be higher than the ex ante performance of younger diversifiers.

\footnotetext{
${ }^{5}$ Our emphasis on using ex ante performance to infer the strength of external constraints does not suggest that internal issues do not affect ex ante performance. Rather, our model exploits the information content of forwardlooking decisions, by both internal and external stakeholders, to infer the sources of organizational rigidity in firms. While internal constraints may influence ex ante performance, they only matter to internal decision-makers if they affect expected ex post performance, while external exchange partners, who lack inside-information, can only make inferences about firms based on their track record.
} 


\subsubsection{Political frictions and ex post profitability}

Internally, organizational decision-makers evaluate strategic changes not only on the basis of expected profits but also on the basis of expected changes to their intra-organizational status, power, and other non-pecuniary benefits (March and Simon, 1958; Jensen and Meckling 1976, Ocasio 1994). In this sense, diversification is influenced not just by the innate quality of new offerings but also by decisionmakers' vested interests. We refer to these internal sources of rigidity driven by intra-organizational relationships vis-à-vis project selection as political frictions.

Powerful managers control resources within firms and generally support established routines that produce reliable results and perpetuate their power (Hannan and Freeman, 1984). The main intuition behind the senescence argument is that organizations develop internal frictions (e.g., precedents, prior compromises) as they age and that these encrustations impede timely collective action (Hannan, 1998). But, managers may support changes that generate private benefits for themselves like job security or additional compensation (e.g., Amihud and Lev, 1981). We, therefore, consider how political frictions can contribute to rigidity with respect to project selection.

Diversified firms face tradeoffs in the allocation of shared resources. For example, discussions with hedge fund industry experts suggest that internal politics influence asset management firms' new product launches because fund managers have an interest in preventing a new fund launch, if they believe that a new fund will distract attention and subtract resources from their legacy fund. And the potential for distraction abounds. Many, if not most, multi-fund hedge funds centralize functions such as sales, research, and legal. At any point in time, sales personnel must choose how to allocate their time; the existence of multiple options may imply risk to future capital-raising for the incumbent fund. Similarly, beyond sales resource allocation, similar tradeoffs present themselves at the level of distribution channels - firms must prioritize distribution efforts within particular channel opportunities, such as the wealth management division of a large broker dealer. Finally, new fund launches, which often struggle or even fail, also create negative externalities to incumbent funds given the potential for tied reputations at the firm level. 
To understand the implications of political frictions with respect to project selection on the ex post profitability of old and young firms in the context of diversification, we assume that firms evaluate opportunities based on expected returns and focus on the expected ex post profitability of a new opportunity. We formalize this idea by assuming each firm generates a single opportunity $x$, where the expected value of $x$ is drawn from a normal distribution $g$ with mean $\mu_{x}$ and variance $\sigma_{x}$.

Political frictions with respect to project selection influence ex post profitability by injecting noise into the selection process when firms consider launching a new product. Some opportunities with expected values below the "apolitical" hurdle rate (i.e., the hurdle rate that would apply absent political concerns) will be implemented because these opportunities are favored by powerful managers acting in their self-interest. In parallel, some opportunities that exceed the apolitical hurdle rate will be rejected because of their potential to undermine the firm's established power structure. If power accumulates within individuals or coalitions as firms age, then older firms' decisions will be more erratic than those of younger firms, in the sense that decisions will be less sensitive to expected profitability and more often based on political compromise.

To be precise, assume as before that both old and young firms draw opportunities from the same distribution of expected values, and fund performance maps directly to profitability. Unless noted, we use identical notation as above. To capture the idea that young firms are less subject to internal politics with respect to project selection, we assume that the young firm implements all opportunities whose expected profitability exceeds the hurdle rate, i.e., a new offering is launched when $x>h_{y}^{x}$, where the superscript $x$ denotes the hurdle is on the random variable $x$ or, equivalently, the expected ex post distribution of performance. Due to internal politics, older firms "sample" from a broader set of opportunities. Therefore, firms will launch a new product with probability $p<1$ if the opportunity's expected value exceeds a hurdle rate $h_{o}^{x}<h_{y}^{x}$. This implies that older firms do not launch some new products which would have met the stricter standard, and launch some products which do not (i.e., because frictions are resolved through compromise). 
Using this framework, we can analyze the effect political activity has on the observed ex post performance of diversifying firms. The expected ex post performance of young diversifiers is:

$$
E_{y}(x \mid d=1)=\int_{h_{y}^{x}}^{\infty} x g(x) d x
$$

For the older diversifiers, the expected ex post performance is given by:

$$
E_{o}(x \mid d=1)=\int_{h_{o}^{x}}^{\infty} x g(x) d x
$$

Finally, given that, $h_{y}^{x}>h_{o}^{x}$, comparing (3) and (4) yields:

$$
E_{o}(x \mid d=1)<E_{y}(x \mid d=1)
$$

If internal politics distorts the opportunity selection process and more so in older firms, then the ex post performance of older diversifiers is lower than that of younger diversifiers, as Figure 3 shows. This noisy filter reduces the frequency of any given opportunity above the apolitical hurdle rate being implemented and increases the probability of a "bad" project being implemented (as represented by the heavy dashed line in Figure 3). Even without any degradation in a firm's ability to implement change over time, older firms will impose a lower mean hurdle rate on diversification choices than younger ones. Consequently, the expected performance of younger diversifiers will exceed that of older ones. ${ }^{6}$

\footnotetext{
${ }^{6}$ Two related aspects of our assumptions are important for the results we derive. First, we assume that $p$ is "not too high" to satisfy our scope condition. Second, we assume that $p$ applies constantly to all projects above the hurdle. While not completely general, both assumptions allow a very large set of potential parameters —including those which are likely most relevant to most empirical contexts, including the one we study.

In terms of the first of these assumptions, the political frictions mechanism implies that while the "political" hurdle rate is lower for older organizations, older organizations only diversify in a subset of the cases above the hurdle. Thus, $p$ must be sufficiently low for our scope condition and Hypothesis 2 to hold. Of course, it is possible, if $p$ is very high, that politically rife older organizations could be more prolific in launching new products. Formally, to satisfy the scope condition, we must have: $\frac{p}{1-p}<\frac{\int_{h_{y}^{x}}^{\infty} g(x) d x}{\int_{h_{o}^{x}}^{\infty} g(x) d x}$. In other words, we need some combination of "small enough" $p$ and "big enough" $h_{o}^{x}$ for the rate of change to be lower in older firms, an assumption we test by studying diversification rates empirically. In general, if one believes that politics is "inefficient," in the sense of destroying some firm surplus, and that there is a dynamic constraint on expansion (e.g., a budget constraint), then $p$ is likely to be low rather than high, in the face of a politicized organization. That said it is beyond the scope of this paper to establish this assumption's generality.

Second, in making the assumption that all projects above the hurdles $h_{i}^{x} i \in\{o, y\}$ are subject to political frictions in constant proportion we are also implicitly assuming that the frequency of projects selected is declining in $x$. While this assumption simplifies the exposition, a more natural assumption might be that there is some probability $p$ that a project will be passed, and that $p$ is an increasing function of the distance a project's return is from a fixed hurdle (e.g., $\left.h_{o}^{x}\right)$. In this alternative setting $p\left(x-h_{o}^{x}\right)$ would have to satisfy conditions such as being bounded
} 
Hypothesis 2: If political frictions with respect to project selection are the primary constraint on change, then the ex post performance of older diversifiers will be lower than the ex post performance of younger diversifiers.

\subsubsection{Implementation costs and ex post performance}

Political frictions with respect to project selection motivate one prediction regarding the relationship between age and post-diversification performance; implementation costs motivate a second. Political frictions as a noisy filter on project selection are manifest in lower quality opportunity evaluation; implementation costs are manifest as an execution penalty that reduces expected project profitability, or returns to the firm net of implementation costs, but does not harm a project's innate quality, or ex post project returns excluding implementation costs, (e.g., returns to investors). As firms age, their ability to adapt may decline because old firms rely extensively on established routines and tacit knowledge from years of trial and error. New offerings are likely to disrupt these routines; accordingly, implementation costs imply that the expected profitability of implementing a strategic change decreases with age. To evaluate the implications of implementation costs on project selection, we build upon our previous analysis to show that equivalent hurdle rates can produce age-varying project quality and, therefore, agevarying ex post performance (i.e., performance excluding implementation costs) following diversification.

We assume that firms of all ages apply equivalent hurdle rates, but older firms incur greater costs of implementing change than younger firms do. Consequently, the net expected value a firm extracts from a given change is decreasing with age. We denote the older firms' implementation cost differential $c$. Thus, if the expected benefit of a young firm implementing change is $x$, then the expected value for an old firm that makes the same change is $x$-c.

below and above by zero and one respectively and would have to be such that $p(x)$ is not so convex such that it is very low between $h_{o}^{x}$ and $h_{y}^{x}$ and then increases sharply above $h_{y}^{x}$. In other words, as long as $p$ does not have very particular form around the apolitical hurdle, the results will hold (e.g., even if $p$ is increasing in $x$ ). In other words, in order to violate this technical assumption, political frictions would have to lead to superior outcomes in terms of project selection than apolitical selection - which, at its face, seems unlikely. 
As shown in Figure 4, the effect of implementation costs on firm adaptation shifts the distribution of expected performance from diversifying generated by older firms leftward by the amount $c$, even though the hurdle rate is the same for both firms. Therefore, the expected ex post performance conditional on diversification for younger firms is given by:

$$
E_{y}(x \mid x>h)=\int_{h}^{\infty} x g(x) d x
$$

and, for older firms is given by:

$$
E_{o}(x-c \mid x-c>h)=\int_{h}^{\infty}(x-c) g(x-c) d x
$$

Based on the properties of the normal distribution and that $h>\mu_{x}$, comparing (6) to (7), implies:

$$
E_{y}(x \mid x>h)<E_{o}(x-c \mid x-c>h) \text {. }
$$

In other words, given higher implementation costs, older firms select higher quality change opportunities than younger firms do, and average ex post project performance is higher for older firms, though profits are lower. Visually one can see both the specific implementation and the fundamental rigidity effects in Figure 4. Consistent with our scope condition, older firms diversify at lower rates - the area under the curves above the hurdle rate is clearly smaller for older firms-but because the change opportunities that older firms select are drawn from points deeper in the right tail of the quality distribution, average ex post project performance is higher. Implementation costs force older firms to select fewer, but better, opportunities than younger firms.

Here, the importance of distinguishing between political frictions with respect to project selection and implementation costs becomes clearer. Implementation costs impact a firm's ability to realize the returns to an equivalent quality change opportunity, but political frictions with respect to project selection influence the firm's propensity to select the highest quality change opportunities. ${ }^{7}$ As a result of

\footnotetext{
${ }^{7}$ To further clarify the distinction we make between political frictions with respect to project selection and implementation costs, note that in the former case, unlike the latter, some projects that are suboptimal from the firm's perspective may be implemented and some optimal projects may be rejected. Thus, any political activity by vested interests within the firm that influences project selection such as logrolling (e.g., supporting others' interests
} 
implementation costs, older firms focus more narrowly on the highest quality change opportunities. This logic motivates our third hypothesis:

Hypothesis 3: If implementation costs are the primary constraint on change, then the ex post performance of older diversifiers will be higher than the ex post performance of younger diversifiers.

Each hypothesized effect is consistent with a negative correlation between age and the diversification rate. Therefore, support for the scope condition and either Hypothesis 1, 2, or 3 is a crucial feature of our framework. Valid alternative explanations must not only motivate a prediction that is equivalent to Hypothesis 1, 2, or 3; they must also be consistent with a negative correlation between organizational age and the change rate, otherwise, the framework's scope condition will not be satisfied.

\section{Data and institutional context}

Hedge funds are, like mutual funds, firms that pool investors' capital for the purpose of investing in financial securities and other assets. In the United States, the \$2.4 trillion hedge fund industry is regulated by the Securities Exchange Commission (SEC), but unlike mutual funds, hedge funds are legally constructed to facilitate extensive short selling, a high degree of leverage, and non-linear performancebased compensation measures (Hedge Fund Research, 2013).

Although hedge funds are not required to publicly report their returns, a large number of funds voluntarily report investor returns to one or more private companies that make their data available by subscription. Investor returns, as opposed to returns to the hedge fund, are extremely helpful for us empirically, as they are exactly the ex ante performance metric external exchange partners (e.g., investors) care about, and, therefore, a good measure for testing Hypothesis 1. Moreover, by stripping out

in exchange for reciprocal support of one's interests), the deployment of political capital or political influence, or side payments that redistribute value within the firm without reducing firm value directly, will all result in a project selection process which is consistent with our formulation of political frictions. If, on the other hand, a project's political support is obtained by "taxing" the firm to form a coalition of parties with competing interests, then we would characterize this form of politics as a politically-motivated implementation cost. Thus, while our framework is able to distinguish political frictions that affect project selection from those that affect the cost of project implementation, our framework does not distinguish multiple forms of implementation costs. 
a hedge fund's costs (e.g., implementation costs), investor returns measure ex post performance directly in our tests of Hypotheses 2 and $3 .^{8}$

The dataset used in this paper integrates two of the most widely used such databases from LipperTASS (TASS) and Hedge Fund Research (HFR). The data from the TASS and HFR data series begin in 1977, but only includes "graveyard" funds - funds that stopped reporting to the data providers for any reason, including fund failure-from 1994. We use the 1994 to 2005 subsample of the data that is free of survivorship bias, although our results are robust to using the full sample. Taking TASS and HFR together, we have coverage on 165,379 firm-months, from 2,814 firms, representing nearly 25 percent of the firms in the industry, over the period 1994-2005. ${ }^{9}$

The hedge fund setting is particularly appealing for studying organizational rigidity. Launching new funds is an important growth strategy for most hedge funds, as it allows them to put capital at risk in a way that increases the chances that the firm will earn additional fees. That said, investors impose meaningful external constraints on hedge fund product diversification by withholding capital from firms that are unconvincing about their strategy for creating value (Shahab 2013). Indeed, based on interviews with limited partners in these firms - the firms' investors - they often expressed reticence about firms diversifying beyond their core fund strategy, particularly because investors often are unable or unwilling to invest in multiple funds from one firm because of diversification concerns. Furthermore, the possibility that internal frictions are increasing in older hedge funds is plausible given de Figueiredo and Rawley's (2011) finding that age is negatively correlated with performance in diversifying firms, and based on our interviews with a number of hedge fund executives. ${ }^{10}$ For example, hedge fund managers note that in

\footnotetext{
${ }^{8}$ Investor returns capture the quality of a firm's underlying investments, and thus are equivalent to project quality. In the absence of implementation costs, project quality maps directly to firm profitability (Hypothesis 2), because of the fee structure of hedge funds (i.e., performance fees increase linearly with positive returns). However, implementation costs drive a wedge between project quality and firm profitability (Hypothesis 3). Thus, investor returns, as a measure of ex post performance, will always capture project quality in our setting, but can only be interpreted as a measure of profitability in the absence of implementation costs.

${ }^{9}$ While the datasets are widely considered the most comprehensive, they do suffer limitations, including back-fill bias, redundancies in fund reporting, which we address in ways consistent with the prevailing literature.

${ }^{10}$ Our work here is both distinct from and complementary to de Figueiredo and Rawley (2011). Their study shows that diversifying hedge funds see a drop in performance after diversification but the performance declines are less
} 
multi-fund firms the same salespeople are almost always responsible for selling multiple funds. Additional funds, therefore, impose coordination costs on the firm in the sense that a multi-fund firm must coordinate sales efforts within and between sales people contemporaneously and over time. Typically allocating sales effort to one sales person implies a direct reduction in sales effort for another fund. ${ }^{11}$

Coordination costs associated with compliance are similar in nature. Compliance personnel are responsible for a firm's adherence to laws governing anti-fraud and anti-manipulation, insider trading, short-selling, margin requirements, etc. In hedge funds, compliance typically also includes riskmanagement functions, and certain aspects of the information technology organization (e.g., software and hardware used to monitor trading). All of these activities are quite intimately involved in the day-to-day operations of the hedge fund. Based on our interviews, it appears that multi-fund architecture is substantially more complex to manage, in part because of the importance of ensuring that trading activity is properly linked to funds (e.g., when one trade could potentially apply to multiple funds). Indeed, at one firm, the shift from one fund to two funds led to the creation of a chief operating officer position and dedicated information technology compliance staff to better manage the complexities inherent in properly allocating trades to funds.

Clearly the coordination costs of integrating activities and resources across multiple products or business units play an important role in our theory. While coordination costs are easy to identify conceptually and anecdotally in hedge funds - the costs associated with sharing back office functions (e.g., information technology, legal and compliance), research, trading, and the sales force-the precise

severe than in firms with a similar return history that did not diversify. Thus, their tests are time-series performance comparisons within firms and cross-sectional performance comparisons between diversifiers and non-diversifiers. In this paper, our main tests are cross-sectional comparisons between diversifiers before and after diversification. While our results demonstrating that the age of the firm influences performance are broadly consistent with theirs, we address a different question: why is the diversification rate negatively correlated with age?

${ }^{11}$ These problems can be exacerbated by the fact that sales people are typically paid on commissions. For example, the fund managers for one firm we interviewed indicated that the sales people would typically sell the 'hot' product - oftentimes new product launches, leaving the others with very limited capital raising efforts. This causes a great deal of influence activity with respect to new fund launches and the management of sales people. 
manifestation of these costs can be difficult for different constituencies to evaluate. External stakeholders use a firm's track record - the one clearly observable signal they have about firm quality — to anticipate how coordination costs associated with diversification might influence the returns on their investments. Politically motivated and powerful insiders consider how coordination costs influence their own compensation (e.g., if the sales force sells the new product to a potential investor the investor may be less likely to buy the legacy product). And, internal principals (e.g., founders with big equity stakes) will focus on future expected coordination costs. Indeed, the types of coordination issues we see within hedge funds are ubiquitous in virtually all diversified firms that share activities and resources across products or business units. $^{12}$

Consistent with the standard definition of diversified firms as multiproduct firms (Teece 1982) and with the literature on mutual fund product diversification (Siggelkow, 2003), we consider hedge fund firms to be diversified when they operate multiple distinct funds. Defining diversification based on product scope is particularly appropriate in this context, as many hedge funds operate their portfolios of funds more like business units than do traditional multiproduct firms. While some functions are almost always shared within a multi-fund firm, such as sales and research, almost every fund exhibits some degree of independence too. Thus, virtually all hedge fund diversification is at least somewhat related and somewhat unrelated. While the relationship between funds is conceptually advantageous, there are empirical ambiguities as to whether a new hedge fund is a "major" new product/business unit that embodies a fundamental change in the organization of the firm, or rather a "minor" new product that is more akin to a product line extension. Although we cannot observe how fundamentally a new fund changes firm organization directly in our data, there is a straightforward empirical measure of distinctiveness that is observable: correlation across investment returns. Below we describe our method for evaluating fund distinctiveness in more detail.

\footnotetext{
${ }^{12}$ Of course, coordination costs will be less important in "pure" conglomerates where the only shared resource is capital. Still, to the extent that diversification influences the efficiency of internal capital markets, our general framework will also apply to conglomerate diversification as well.
} 


\subsection{Measures}

To ensure that a new fund is distinct from a firm's existing portfolio of funds, and is, therefore, a major diversification event, we measure distinctiveness based on the pair-wise correlation of the time series of returns between each fund and every other fund in the firm's portfolio. Only new fund launches that are sufficiently distinct from all existing funds in the firm are considered major diversification events for the purposes of our analysis. Specifically, our primary correlation measure of distinctiveness is based on the correlations amongst or between funds' raw return histories. We also use an alternative measure based on the correlations amongst or between funds' excess return histories, after adjusting for the eight standard common factors used in hedge fund asset pricing, (described in more detail below). We use these two correlation measures to compute three tiers of relatedness for all 2,302 new fund launches in our sample. $^{13}$

New funds that have a return history that is less correlated with other funds in the firm than with the time series of "passive" predicted returns using the eight common factors are characterized as unrelated diversification events. The intuition for using an index of common factors as a benchmark for measuring distinctiveness is that if a fund is more similar to another fund in the same firm than it is to the passive index, defined by the common factors, then the new fund is related to the existing fund-its investment strategy is more like the existing fund's than it is like the "typical" fund's investment strategy. The converse is also true, if a fund is less related to every other fund in the same firm than it is to the typical fund, then it is a distinctive new offering. Thus, we call unrelated diversification events with pairwise correlations below the passive index-on average a 0.35 raw return correlation- "explorative" diversification in the language of March (1991). There are 573 such explorative new fund launches.

At the other end of the correlation spectrum, there are 1,250 new fund launches that are "highlyrelated" to existing funds in the same firms, which we define as having a raw return correlation of 0.75 or above. The 0.75 raw return cutoff follows directly from our measure of explorative diversification, and it

\footnotetext{
${ }^{13}$ We take a revealed approach to measuring distinctiveness, as opposed to a self-reported approach. However, the results are robust to using self-identified fund investment categories to measure distinctiveness.
} 
approximates a conservative, but natural breakpoint: a 0.50 excess return correlation - the point at which a new fund is half correlated and half uncorrelated with an existing fund. ${ }^{14}$ Because highly-related diversification events may be more similar in spirit to product line extensions, rather than core changes to the firm's set of product offerings, we do not consider these new fund launches to be major diversification events in our analyses. ${ }^{15}$

New funds with a raw return correlation of less than 0.75 , but above the correlation with the passive benchmark, based on the common factors, are in an intermediate zone- they are related, but not highly related, new product offerings. These 479 diversification events are not simply product line extensions, they are essentially new, but related, business units, and are therefore properly recognized as major diversification events that represent core changes in the internal organization of the firm. Yet, because these funds are more similar to the firm's existing offerings than the explorative diversification events, we call these new fund launches "exploitative" (major) diversification events. For our main analyses we use all 1,152 (573+479) major diversification events, but in subsequent analyses we use the exploration/exploitation dichotomy to further probe rigidity mechanisms in our sample, as well as to provide a robustness check on our definition of major diversification events.

Based on the definition of a major diversification event described above, we use two measures of diversification, an instantaneous measure (Diversify), a dummy variable that is equal to one in the month in which a firm launches a new fund and zero otherwise, and a categorical variable (Diversified) that is equal to one in all months subsequent to the firm's first diversification event, and zero otherwise. Of the 1,152 major diversification events in our sample involving 591 firms, about 35 percent of firms launch

\footnotetext{
${ }^{14}$ While the set of fund launches above or below the cut point is slightly different using a 0.50 excess return correlation as the breakpoint, none of the results are affected in a meaningful way by using this alternative measure.

${ }^{15}$ All of the results are robust to including these 1,250 diversification events in the analysis. But, by excluding these events our analysis more closely matches the conceptual precedent of the organizational change literature in the sense that we restrict our analysis to core organizational changes. The results are also robust to more or less restrictive definitions of "highly-related" (e.g., lower or higher correlation cutoff values).
} 
more than one distinctive new fund, and therefore experience multiple major diversification events. ${ }^{16}$ As we demonstrate below the results are not sensitive to restricting the event space to first diversification events only, or to excluding firms that subsequently close one or more funds.

Our key explanatory variable is firm age, measured as the number of years since the firm was founded or, non-parametrically, as a vector of categorical variables. Age also enters as an interaction term with Diversify, and as dummy variable (age_old) that is equal to one when a firm launches a new product and is above the median age and is zero otherwise. The sample includes 522 major new product introductions for firms that were older than the median age at the time of diversification and 630 major new product introductions for firms that were younger than the median age at the time of diversification.

Our hypotheses evaluate the relationships amongst diversification, age, and performance. Because there is general agreement in the literature that investors price financial assets controlling for systematic risk exposure, we use risk-adjusted excess returns from a standard asset pricing model as our baseline measure of firm performance. However, hedge funds may also be exposed to non-systematic risks that are not priced by standard market benchmarks. If funds take on significant non-systematic risks they may appear to generate higher average excess returns that are really an artifact of model mispricing. We, therefore, account for the non-systematic riskiness of a fund's underlying investments using an alternative performance measure: a dynamic version of the information ratio, which divides the fund's excess return in any time period by the standard deviation of the fund's excess returns. We also control for biases that may arise due to self-reporting, including serial correlation in the time series of returns using an autoregressive lag one (AR1) correction and for reporting biases, particularly backfill and timing biases, by dropping the first twelve reported monthly returns.

Our baseline performance benchmark follows the emerging standard for assessing hedge fund performance, based on Fung and Hsieh's (2001) 7-factor asset pricing model, which is specifically

\footnotetext{
${ }^{16}$ For most firms launching a new fund is preferable to running a multi-strategy fund, because expected performance fees are increasing with the number of funds. Thus, while multi-strategy funds are diversified investment vehicles, they are not meaningfully diversified organizationally in the sense in which we are interested: they have not launched a distinctive new product that represents a core change in the internal organization of the firm.
} 
designed for pricing risk in hedge funds by controlling for exposures to equity, bond, commodity and option-based risk factors. We augment Fung and Hsieh's (2001) model by including a "traded liquidity factor", which controls for a fund's exposure to illiquidity risk. Excess returns are:

$$
R_{i t}=a_{i}+R_{f t}+X_{t} \boldsymbol{B}_{i}+e_{i t}
$$

where $i$ and $t$ index funds and time (in months) respectively; $R_{i}$ is a fund's raw return from TASS and HFR and the vector $\boldsymbol{X}$ contains the seven risk factors from Hseih's data library and the traded liquidity factor. ${ }^{17}$ The term $a_{i}$ is the time invariant component of a fund's excess performance and $e$ is a mean-zero residual. We compute $a$, the coefficients on $X$ and $e$ by running fund-level longitudinal regressions. Excess returns $Y$ for firm $i$ in any period $t$ are defined as $Y_{i t}=a_{i}+e_{i t}$, where excess return captures the combination of a fund's skill and luck relative to a market benchmark. We call the resulting measure "8factor excess returns." We then compute the information ratio as excess returns $\left(Y_{i t}\right)$ divided by the standard deviation of excess returns. Both the information ratio and excess returns are winsorized at $1 \%$ tails to control for extreme values, though doing so has no meaningful impact on our results. Finally, firm performance is the average of fund performance in multi-fund firms.

Hypothesis 1 predicts that, conditional on launching a new product; older firms' ex ante performance will exceed that of younger firms. To test this prediction we use a standard measure of average historical excess returns, average cumulative abnormal returns $(C A R)$, as an explanatory variable in our regressions of ex ante performance and age on diversification. At the fund level $C A R=\Sigma Y_{i n} / n$, the sum of $n$ lagged excess returns divided by the number of months the fund was in operation at time $t$, up to a maximum of twenty four months. ${ }^{18}$ An equal weighted average of fund returns gives a firm-level CAR. For Hypotheses 2 and 3 we define ex post returns analogously.

\footnotetext{
${ }^{17}$ Hseih's data library is available at http://faculty.fuqua.duke.edu/ dah7/HFData.htm. The traded liquidity data are available from Robert Stambaugh at http://finance.wharton.upenn.edu/ stambaug/ liq_data_1962_2008.txt.

${ }^{18}$ Using two-years of return data in $C A R$ represents an imperfect tradeoff between including more information about the fund's historical track record by including longer performance lags and reducing the amount of stale information in the firms track record. $C A R$ measures with longer time lags produce results very similar to those reported here.
} 


\subsection{Descriptive statistics}

Table 1 shows descriptive statistics for the main sample at the firm-month level. Average age is 5.6 years, the average number of funds is 2.6, average excess returns are 44 basis points per month (or $0.44 \%$ ), and the average information ratio is 18 basis points per month. Table 1 also shows descriptive statistics for the control variables that might influence diversification rates or performance directly or indirectly, including: firm size, measured by assets under management; Amburgey, et. al.'s (1993) waiting time measure (log time since the firm's last fund launch); firm scope (number of funds); the standard deviation of firm ex ante performance; three variables that measure the firm's product mix; a dummy for whether the firm entered a multi-fund firm; time (year); and region (USA headquarters dummy). CAR also enters as a control in the baseline regression predicting diversification and in the matching model (discussed in detail below). The mean of assets under management (AUM) is $\$ 3.2 \mathrm{~B}$, with a maximum of $\$ 63.8$ billion. To control for trading strategy composition effects, we use a continuous variable (specialist) $[0,1]$ that captures the fraction of funds in the firm's portfolio, by month, that are devoted to specialty trading practices. To calculate specialist we categorize funds into three sets. Fund-of-funds are products that invest in other hedge funds. Long/short funds are general purpose hedge funds that take long positions in assets, much like a mutual fund and short assets (typically equities) that fund managers believe are overvalued. All other strategies are grouped together as specialty funds, and specialist is the fraction of specialist funds within a firm in a given month. We also include a categorical variable that is equal to one if a firm's headquarters is in the USA and zero otherwise (HQ_USA), and a categorical variable (diversified_entrant), that is equal to one if a firm is diversified upon entry.

\section{Empirical design}

We theorize that major organizational changes are particularly challenging for older firms inducing them to launch new products less frequently than younger firms. To validate the scope conditions for this premise, we estimate the impact of age on a hedge fund's propensity to launch new a new fund using several different empirical specifications: a pooled cross-sectional linear probability model, a 
differences-in-differences estimator with firm fixed effects, a pooled discrete response regression, a logit model with firm fixed effects, and two specifications focusing on the firm's first diversification event.

Because unobservable firm-specific heterogeneity (e.g., firm-specific quality) is a potential confound for causal estimation our baseline OLS estimator includes a firm fixed-effect of the form:

$$
\operatorname{DIVERSIFY}_{i t}=a+\lambda_{i}+\boldsymbol{T}_{\boldsymbol{t}}+\beta_{1} A G E_{i t}+\boldsymbol{X}_{\boldsymbol{c}} \boldsymbol{B}_{\boldsymbol{c}}+\varepsilon_{i t},
$$

where $i$ indexes firms, and $\mathrm{t}$ calendar time (in months), $\lambda$ is a firm fixed effect, $T$ is a vector of year fixed effects, $A G E$ is our key explanatory variable, and $X_{c}$ is a vector of controls as described above, and $\varepsilon$ is the residual. Other specifications (e.g., logit, proportional hazards) are standard as well, and all include the same set of controls and use robust standard errors clustered at the firm level.

The differences-in-differences estimator corrects for time-invariant firm-specific heterogeneity, but cannot control directly for time-varying sources of heterogeneity that may be correlated with both firm age and the decision to diversify. ${ }^{19}$ While we do not have a pure experimental design, we do include time-varying controls that should be correlated with quality $-C A R$ and assets under management $—$ which reduce the risk of bias from changes in firm quality that may be correlated with product diversification.

Once we establish that firms diversify at a slower rate as they age, we turn to our main research question - why is adaptation difficult? To do so we first examine how ex ante performance, measured by cumulative abnormal return, $C A R$, influences the instantaneous diversification rate for young versus old firms using multinomial logit and OLS specifications.

To allow for a flexible set of coefficient estimates on the explanatory variable $C A R$ for multiple dependent variables, we compare the ex ante performance of young diversifiers against old diversifiers relative to non-diversifiers using the multinomial model:

$$
\operatorname{Pr}\left(y=j \mid \boldsymbol{X}_{i t}\right)=\exp \left(\boldsymbol{X B}_{i j t}\right) /\left[1+\Sigma_{h} \exp \left(\boldsymbol{X} \boldsymbol{B}_{i h t}\right),\right.
$$

\footnotetext{
${ }^{19}$ For example, if firm quality diminishes over time as portfolio managers leave the firm then a naïve differences-indifferences estimator might overstate the causal effect of age on the propensity to diversify. On the other hand if quality increases over time due to survival effects then our results will be understated.
} 
where $i$ indexes firms, $\mathrm{t}$ indexes time (years), $j=1, \ldots J$, indexes discrete change in scope outcomes, $h$ counts from 1 to $J ; X$ contains the same vector of controls as in (10), including the explanatory variable $C A R ; y=0$ in firm-months where there is no diversification, and $y=J$ when firms reduce their scope. In our baseline specification $y=1$ when the firm diversifies and is below the median age, and $y=2$ when the firm diversifies and is above the median age. Standard errors are robust and clustered by firm. To be certain the effects are not being driven by fund closures through churning effects, we also estimate the same relationship excluding firms that close at least one fund.

The coefficient on $C A R$ tells us how the firm's track record influences its diversification decisions for old and young firms. If the coefficient on $C A R$ is larger for older firms compared to younger firms, it would indicate that investors punish older firms by forcing them to outperform young firms in order to earn the right to diversify. On the other hand, if the coefficient on $C A R$ is smaller for older firms, it would suggest that investors value long track records and fund diversification efforts of older firms, even when their most recent observable performance lags behind younger firms.

A multiple dependent variable specification has some advantages given the nature of our predictions, but we do want to verify that the results are not being driven by unobservable firm-specific heterogeneity (e.g., young firms are higher quality firms). Unfortunately fixed effects estimation is computationally intensive and difficult to interpret in a multinomial logit specification; however, because the key comparison of interest is between the performance of old and young diversifiers, we can test Hypothesis 1 using OLS by constructing a sample that consists of just the set of diversification events, and redefining the dependent variable to be equal to one when there is a diversification event above the median age and zero for all other diversification events. By including or excluding firm fixed effects in this OLS specification - with firm fixed effects, identification comes from comparing the performance of the same firm that diversified when it was "young" versus when it was "old"-we can explicitly test whether firmspecific heterogeneity biases the results. If there is no bias from firm-specific effects, then a negative difference between the coefficients on $C A R$ in the multinomial logit specification can be interpreted as the premium young firms must generate to be on equal footing with older firms in external capital markets. 
As above, in establishing our scope condition, we also specify an OLS regression restricting the set of major diversification events to include first-time diversifiers to facilitate between-firm comparisons.

Finally, to test our second and third hypotheses we evaluate how young and old firms perform after they diversify. In the ideal experiment we would randomly assign identical old and young firms new funds and measure the difference in their subsequent performance. In practice, we do not have random assignment. Firms choose whether to diversify, based on how exchange partners external to the firm perceive them and how they expect to perform ex post. We can, however, control for selection effects that might bias naïve estimates of age's effects on diversification and performance by matching treatment (i.e., old diversifiers) to control (i.e., young diversifiers) group observations based on observable ex ante differences between old and young firms that subsequently diversify. In the absence of omitted variable bias from unobservable differences between firms, we can interpret the matched sample correlation between age and ex post performance as a causal relationship (Rosenbaum and Rubin 1983).

Before controlling for selection on observables we estimate the (endogenous) correlation between age and diversification with the pooled cross-sectional model:

$$
Y_{i t}=a+\text { DIVERSIFIED }_{i t}+\beta_{1} A G E_{i t}+\beta_{2}\left(A G E_{i t} x \text { DIVERSIFIED } i t\right)+\boldsymbol{X}_{c} \boldsymbol{B}_{c}+\varepsilon_{i t},
$$

where $i$ and $t$ index firms and years, respectively, $Y$ is firm performance, measured as either excess returns or the information ratio, DIVERSIFIED is a dummy if a firm has previously diversified, and $A G E$ is as above. $\boldsymbol{X}_{\boldsymbol{c}}$ contains the same vector of control as above (including year fixed effects). Expression (12) reverses the direction of causality between performance and age compared to expression (11), but in expression (12) performance is measured ex post-following diversification (i.e., when DIVERSIFEID = 1), whereas in expressions (11) we focus on ex ante performance (as measured by $C A R$ ) as either a control variable or an explanatory variable influencing the instantaneous diversification rate (i.e., DIVERSIFED $=1$ ). Thus, to estimate how old diversifiers perform relative to young diversifiers we consider both the main effect of $A G E$ and the marginal effect of AGE $x$ DIVERSIFIED.

However, we know that (12) is subject to bias due to the endogeneity of the firm's scope decisions (Campa and Kedia 2002). Therefore, we implement a test on ex post performance that controls for 
selection bias by matching old diversifiers to young diversifiers on all their observable ex ante characteristics using Coarsened Exact Matching (CEM). CEM matches old and young diversifiers that have the exact same ex ante characteristics, as opposed to matching on the probability of selecting into the treatment (i.e., diversifying when old) as in the more familiar propensity score matching (Iacus, et. al., 2012). Using CEM to generate the matched sample suits our purposes because it allows us to include multiple diversification events on the same firm in a computationally efficient way; creating a valid counterfactual without balancing on a covariate-by-covariate basis.

We specify that the number of control group matches must be proportional to the number of treatment group observations on a strata by strata basis, based on performance deciles, quartiles of the standard deviation of ex ante firm performance, size deciles, calendar time quartiles, firm scope deciles, a USA headquarters dummy, management fee and incentive fee quartiles, and median splits of fund of funds and long/short trading strategy proportions.

The matching works well in the sense that it eliminates the statistical differences between most of the covariates in old versus young diversifying firms. Before matching eleven of thirteen covariates were statistically different, after matching only three are statistically different, and two of those three covariates are far more similar after matching than before (see Table 2). After successfully matching treatment group to control group observations all the observations are conditioned on the firms being diversified, which allows us to drop DIVERSIFIED, and AGE $x$ DIVERSIFIED from (12) and estimate the causal effect of age on performance in diversified firms directly by simply examining the coefficient on $A G E$.

To probe the results further we also use the same matched sample to estimate the effect of age on ex post performance at the fund level in two ways. First, we perform the fund-level analogue of our firmlevel analysis, by evaluating the performance of new funds from old firms compared to new funds from young firms. Second, we test to see whether diversification influences the performance of existing funds differently in old diversifiers compared to existing funds in young diversifiers. 


\section{Results}

Table 3 displays the results for the OLS and survival-time models of AGE on DIVERSIFY. Column 1 shows that the new product introduction rate falls by a precisely estimated seven one-hundredths of $1 \%$ for each additional year the firm ages in a pooled cross-sectional specification. Relative to the baseline new product introduction rate of $0.63 \%(1,052 / 167,559)$, increasing age by one year reduces the baseline new product introduction rate by about $12 \%$. The differences-in-differences estimate of the effect of $A G E$ on DIVERSIFY in column 2 reveals that omitting the firm fixed effect from the estimate of age on the propensity to introduce a new product biases the coefficient estimate on age toward zero- the effect size is more than three times the size (more negative) after controlling for firm-specific heterogeneity and still precisely estimated. These results are further corroborated by the logit and fixed effects logit models of the same sign and significance as the OLS estimates (columns 3 and 4, respectively).

Restricting the set of major diversification events to include only the first event from each firm generates a smaller, though still precisely estimated, point estimate on age in the pooled OLS regression (column 5) of minus four one-hundredths of $1 \%$, but the economic interpretation remains very similar-a one year increase in firm age leads to a $12 \%$ decline in the firm's initial diversification rate (i.e., their first major expansion from one to two funds). Using the same sample, but controlling for right censoring with an exponential model (column 6) generates a the coefficient estimate of -0.175 , which means that as firms age one year from the mean age (5.6 years) their propensity to diversify falls by $6 \%\left(e^{5.6 x-0.175}-e^{6.6 x-0.175}\right)$.

We also want to understand the relative magnitude of internal organizational factors compared to external effects on the decision to introduce a new fund. Column 1 of Table 4 shows the results of a multinomial logit of ex ante performance on the decision to diversify for firms that were older than the median age at the time of diversification compared to firms that were younger than the median age at the time of diversification, conditioning out months where firm scope was reduced due to fund closures, compared to the baseline case of no changes in firm scope. Marginal effects are reported. While younger firms outperform in the twenty-four months prior to launching a new fund older diversifiers' ex ante performance is indistinguishable from the baseline. The difference between the two coefficients is 
negative $0.00062(-0.062 \%)$, is precisely estimated, and the specification passes the independence of irrelevant alternatives (IIA) test. The economic interpretation of the difference in the coefficients is that a young firm is approximately $10 \%$ less likely to diversify $(-0.062 \% / 0.63 \%)$ than an older firm with the same ex ante performance.

Column 2 reports the OLS analysis on just the 1,052 major diversification events from the 591 diversifying firms. The coefficient on CAR is -0.078 and is precisely estimated. The interpretation is that older diversifiers underperform younger diversifiers by 8 basis points per month on average (approximately $1 \%$ per year). Including firm fixed effects in column 3 has a small impact on the point estimate (-0.071), and it remains precisely estimated, but the interpretation is slightly different: as a firm ages its ex ante hurdle rate required to launch a new fund falls by 7 basis point per month.

In column 4 we show that the results are robust to excluding the 1,011 firms that close funds at some point to make sure the results are not driven by firms launching new funds and subsequently closing legacy funds ("churning"). Although the number of major events in the sample is reduced by $45 \%$ the results are very similar. Finally, in column 5 we restrict the sample to first-time diversification events only, and find a result very similar to the regression in column 2, which includes all major diversification events. In all five specifications the results are qualitatively the same: capital markets reward firms with longer track records, allowing them to diversify even when their performance is worse than younger firms by an economically and statistically significant margin. Thus, the ex ante performance results in Table 4 suggest that external investors' requirements do not constrain horizontal expansion in aging firms.

In Table 5 we present estimates of the effect of new product launches and age on ex post firm and fund performance. The baseline (endogenous) results on the full sample of firms are equivocal; performance, as measured by excess returns, is negatively correlated with age (column 1), but is positively correlated with performance, as measured by the information ratio (column 2). However, age effects swamp the marginal effect of age on diversification. Of course, endogenous selection effects are likely to lead to a significant bias in our estimates. In columns 3 and 4 we estimate of the effect of age on ex post performance in diversified firms, after adjusting for selection effects, by matching exactly on all 
observable firm characteristics in the data ex ante. The matched sample results show that older firms underperform ex post, as measured by excess returns (column 3) or the information ratio (column4), at a precisely estimated rate of approximately 1 basis point per month.

At the fund-level we find that diversification negatively impacts ex post performance through two channels. New fund performance is worse in older diversifiers than in younger diversifiers by four-tenths of a basis point per month (column 5), suggesting that older firms choose lower quality projects than younger firms. Interestingly diversification also leads to lower performance in legacy funds in older firms compared to legacy funds in younger diversifiers by seventh-tenths of a basis point per month (column 6), which suggests that old firms also choose projects that have less synergy with their existing product portfolio. The fund-level results are interesting because they suggest that the "noisy filter" of political frictions not only saddle older firms with lower-quality projects on a stand-alone basis, they also rob the firm of opportunities to create value at the corporate level through inter-fund coordination.

Of course, the estimates in Table 5 are still potentially biased from the effect of omitting unobservable firm characteristics that are correlated with both age and performance. Fortunately, the most likely threat to inference should work against finding support for our hypotheses. Presumably, older firms possess certain positive qualities that are unobservable to the econometrician, but are observable to investors, which facilitate their survival. This unobservable appeal of older firms might also explain why older firms can diversify with poorer track records than younger firms (i.e., in Table 4). Thus, the most obvious bias from endogeneity should attenuate the age effects and bias our results toward zero.

To further probe the evidence for the mechanisms we also split the sample based on whether major new fund launches are characterized as exploration versus exploitation as defined above, and evaluate the results on each sub-sample of major diversification events. Starting from the idea that older firms are better at exploitation than exploration due to the difficulties older firms have adapting long-standing routines (Sørenson and Stuart, 2000), the model can easily be extended to make predictions about the relative effect of age on explorative versus exploitative diversification events. Given higher implementation costs, and therefore lower chances of success with diversification, if either internal 
implementation costs or external constraints are the primary source of rigidity in our sample, age effects should be larger (more negative) for explorative than for exploitative diversification. On the other hand, because political frictions with respect to project selection will be more severe when a new product necessitates more extensive coordination, the prediction is reversed if political frictions are the key driver of rigidity. Similarly, because of anticipated adaptation costs, following the logic of Hypothesis 1 , ex ante performance results should be better for explorative diversification than for exploitative diversification, if external constraints are the primary source of rigidity.

Table 6 runs each of our main analyses from tables 3, 4 and 5 on explorative and exploitative diversification events. In all cases the results hold for each subsample and the estimates are never statistically different from one another by subsample, but are nevertheless informative. Age is negatively correlated with propensity to diversify, and precisely estimated, for both explorative and exploitative diversification events (columns 1 and 2, respectively). The coefficient on Age is two times larger (in absolute value) for exploitative diversification (-0.0016) compared to explorative diversification (0.0008). Though the two point estimates are not statistically different from one another-the t-statistic on the difference is 1.60 - the results are more consistent with political frictions with respect to project selection than with implementation costs or external constraints. Ex ante performance (i.e., CAR) is more negative for explorative diversification than for exploitative (columns 3 and 4, respectively), which is also inconsistent with the external constraints mechanism, though the point estimates are not statistically different. Finally, for completeness we also report that matched ex post performance is slightly worse for exploitative diversification at -1.4 basis points per month (column 6) than for explorative diversification, which comes in at -1.1 basis points per month. Both point estimates are precisely estimated, but here again the difference between the point estimates is not statistically significant. In general the relative uniformity of the results across the two subsamples speaks to the importance of political frictions with respect to project selection as a source of organizational rigidity in the context of hedge funds.

In sum, the evidence on performance, new product introductions, and age shows that older firms diversify at a slower rate than younger firms, with worse track records ex ante, and underperform ex post, 
results that support the idea that rigidity in older organizations is primarily attributable to internal factors and, more specifically, to political frictions with respect to project selection.

\section{Discussion}

The evidence from our study is consistent with the view that hedge fund diversification efforts are primarily constrained by political frictions that inject noise into older firms' evaluations of strategic change opportunities. But, political frictions with respect to project selection are not observed directly, raising the question of whether or not alternative explanations that make observationally equivalent predictions are viable, or if other plausible assumptions motivate different predictions. For example, we have assumed that political frictions with respect to project selection are germane to a wide range of potential projects but, in reality, political frictions might be more salient when a project's expected return is "close" to the hurdle rate. As we discuss in detail in footnote 6 above, barring an unusual technical violation, our simplifying assumption is fairly innocuous - even if the selection process is such that better projects are more likely to pass through the political process than worse projects, all of the framework's predictions still hold.

Another important assumption is that exchange partners hold older firms to a higher standard than younger firms, demanding higher ex ante performance in return for supporting a new project. One might alternatively assume, consistent with Stinchombe's (1965) observations on the liability of newness, that younger firms are held to a higher standard. Here, the importance of our key scope condition - that the rate of change is declining in older firms before our framework applies-becomes clear. Our model applies only in circumstances where older firms change less often (e.g., diversify at a lower rate) than younger firms, a condition that is unlikely to hold if older firms are held to lower standards than younger ones. Thus, we do not dispute that the liability of newness will dominate the liability of old age in a particular setting. Nor do we claim that exchange partners will always hold older firms to a higher standard. We only assert that exchange partner reservations about older firms is the correct hypothesis to test when there is evidence for the liability of old age-that is when our scope condition is met. Relatedly, we would not expect that the rigidity effect will always be so severe as to lead older firms to 
exit an industry whenever confronted by a major strategic change. Rather, our scope condition implies that, on the margin, older firms will be more rigid, and therefore less able to adapt to environmental shocks. Our conceptual framework follows directly from that (testable) premise, though it is fair to note that our framework does not apply to every circumstance where political frictions with respect to project selection are the key driver of rigidity in a firm (i.e., because the context will fail the scope condition when $p$ is "too high."

Another important assumption we make is that the firm holds asymmetric information regarding its quality, which is not fully communicated to external exchange partners. Because information asymmetry is potentially inefficient, one might reasonably wonder why the firm simply does not convey such information to outsiders. Here our logic follows closely from agency theory: information asymmetries exist between principals (e.g., investors) and agents (e.g., managers). The real issue is not whether the firm can convey information to external exchange partners but, rather, whether the firm can do so credibly given strong incentives to mislead potential partners. For example, if investors believed all managers' claims, then managers would face very strong incentives to claim the capability to launch more funds in order to raise more assets to manage and more fees to collect. But, because investors are reasonably skeptical of such claims, managers cannot fully convey information about capabilities to investors through cheap talk, which leads to asymmetric information in equilibrium.

Yet another assumption that might warrant more scrutiny relates to exactly how political frictions operate inside of organizations. Consistent with Gibbons's (1999) observation that firms are messy (i.e., first-best outcomes are not always realized) but not a mystery (i.e., outcomes are predictable), we characterize political frictions as a noisy filtering mechanism that excludes some projects above the "apolitical" hurdle rate and also includes some projects below that apolitical hurdle rate, leading to a lower realized hurdle rate on project selection. Politics might also act in other ways. For example, political wrangling could lead to what is essentially an internal market for project selection effectuated by side payments between powerful insiders. While side payments that are simply redistributive amongst insiders are incorporated into the concept of political frictions we test, if they do in fact influence project 
selection, under certain conditions side payments may represent a political cost that is conceptually different from the noisy filter concept, but rather is accommodated in our model as an implementation cost. For example, if side payments act as a tax on the firm, instead of simply redistributing value amongst insiders, the "tax" will lower the expected profitability of any particular new project and, as a result of this implementation cost, firms will select deeper into the right tail of the performance distribution. Thus, we must be careful to characterize the evidence we find in this paper as being consistent with political frictions as a noisy filter and not political implementation costs.

Our approach deals with alternative assumptions, by either accommodating them, or falsifying them, but potential alternative explanations also warrant consideration. For example, if older firms have higher implementation costs, and knowing this, they both attempt fewer diversifications and are less successful at the ones they do attempt, then one might expect the same results we have found. Indeed, if our theory concerned only new fund profitability then it would be difficult to distinguish between implementation costs and the noisy filter of political frictions. But, while firms select projects based on profitability, Hypothesis 3, the implementation costs hypothesis, does not make a prediction about project profitability, but, rather, makes a prediction about the quality of projects selected and, therefore, ex post project performance (i.e., excluding implementation costs). For the purposes of testing Hypothesis 1 (external constraints) and Hypothesis 2 (political frictions), there is a direct relationship between project quality and profitability, because implementation frictions do not operate through these channels. But, for Hypothesis 3 (implementation costs), implementation costs drive a wedge between profitability and project quality. As a result, implementation costs always lead to higher quality projects ceteris paribus, (e.g., in terms of returns to investors), even though all projects face the same profitability hurdle. Thus, ex post performance will be higher, not lower, when firms face implementation costs.

Another possibility is that older firms are more bureaucratic, and hence slower to make decisions on diversification, and yet have more slack resources, allowing them to sample from a broader set of opportunities. If true, we would observe both a lower diversification rate and relatively poor postdiversification performance amongst older firms. While bureaucratic frictions may be conceptually 
equivalent to political frictions when they are intentional (e.g., when bureaucrats lower the hurdle rate on a case-by-case basis to favor pet projects), or to implementation costs when the costs of bureaucracy are anticipated (e.g., when bureaucracy drives a wedge between project quality and project profitability in expectation), and therefore, accommodated by our model, it is plausible that unanticipated unintentional bureaucratic frictions coupled with slack resources could be a confounding factor in our analysis. For example, if a firm had slack resources, and its governing bureaucrats were "lazy" or erratic, in the sense that they selected projects in a relatively haphazard manner, independent of expected implementation costs and their own personal motivations, it would be difficult to separate bureaucratic frictions from political frictions empirically. However, one key institutional detail militates against this possibilityalmost all new hedge funds require substantial external capital rather than being funded out of free cash flows. Thus, empirically, slack resources do not play a major role in our setting, and the observed "sampling" behavior is more consistent with a political frictions explanation than with a slack resources explanation. However, we do caution that bureaucratic frictions that are neither politically motivated, nor well anticipated, are potentially important to consider, particularly in settings where firms have market power and can fund projects out of free cash flows.

Multiple alternative explanations might account for why older firms perform worse than younger firms prior to diversifying (e.g., organizational learning, legitimacy, problemistic search). But, crucially, viable alternatives must not only generate the performance results predicted by Hypothesis 1, 2, or 3; they must also satisfy the scope condition that older firms diversify at a lower rate than younger firms. Standard alternative explanations (and many non-standard explanations that we are aware of) satisfy only one of these conditions. In this way, our framework's single scope condition enables researchers to adjudicate among diverse theoretical arguments motivated by prior work in organizational theory and strategic management while also allowing for these arguments to be supported in other settings. 


\section{Conclusion}

This study examines organizational impediments to strategic change. We consider how three commonly-invoked, rigidity-producing mechanisms-exchange partner constraints, political frictions, and implementation costs-generate different patterns of firm performance. Applying our general framework to age-based rigidity in hedge fund product diversification, we identify political frictions with respect to project selection as the dominant source of firm rigidity.

The results are consistent with the classic literature on organizational decision-making (Cyert and March, 1963), which conceptualizes the firm as a collection of interest groups with competing objectives, and the ecological literature on organizational change (e.g., Hannan and Freeman, 1984), which recognizes organizational politics and aging as rigidity-generating mechanisms. But, the idea that aging catalyzes bureaucratic processes by subjecting project evaluation to a noisy filter is novel. We believe that hedge funds present a conservative test of political influences on firm decision-making because hedge funds typically exhibit limited hierarchical differentiation of executives and employees and strong incentive alignment between managers and investors. Moreover, our operationalization of political frictions is quite conservative, as we limit ourselves to only noisy filter effects, and not political effects associated with implementation costs. The fact that we still find that hedge funds are subject to political frictions suggests that organizational politics play a broader role in organizational rigidity than has been previously documented.

This study demonstrates how our conceptual framework can disentangle different rigidity mechanisms in a wide variety of settings. Of course, the primary source of rigidity likely differs by context, and the specific nature of other strategic changes will not always be closely mirrored by diversification activity. For example, hedge funds are inherently ambiguous organizational forms (Smith, 2011), perhaps with lesser exchange partner obligations than, say, airlines, for-hire trucking companies, or law firms - firms that prior work demonstrates to be rigid. And hedge fund product diversification is likely to be qualitatively different from technology innovation in manufacturing firms, for example, along a number of dimensions that should be considered carefully when applying our framework to other 
settings. As always, the institutional details of a particular context should inform specific interpretations of the empirical tests. For example, hedge funds are an ideal laboratory for studying the mechanisms behind organizational rigidity, in part because ex post performance is informative about project quality, which allows us to run a horse race between political frictions with respect to project selection and implementation costs. Other contexts where high fixed costs make revenue-based measures of project quality meaningful are also well suited for this kind of analysis-for example the pharmaceutical industry, or the software industry.

Importantly, our framework can guide studies of how other organizational characteristics (e.g., size, location) contribute to rigidity. For example, one could use our framework to study innovation activities, technology adoption, divestitures, or policy changes. Subject to a single scope condition (e.g., a significant negative correlation between change rates and an organizational covariate of interest), the framework can identify the primary locus of rigidity on many discrete strategic changes in a wide variety of contexts. 


\section{References}

Amburgey, T.L, D.Kelly, and W. P. Barnett. 1993. Resetting the clock: The dynamics of organizational change and failure. Admin. Sci. Quarterly, 38(1): 51-73.

Amihud, Y., and B. Lev. 1981. Risk reduction as a managerial motive for conglomerate mergers. The Bell Journal of Economics 12(2): 605-617.

Argyres, N.S and J. Liebeskind. 1999. Contractual commitments, bargaining power, and governance inseparability: Incorporating history into transaction cost theory. Academy of Management Review 24(1): 49-63.

Barnett, WP and GR Carroll. 1995. Modeling internal organizational change. Ann. Rev. of Sociology, 21: 217-236.

Barron, D.N. E. West, and M. T. Hannan. 1994. A time to grow and a time to die: Growth and mortality of credit unions in New York City, 1914-1990. American Journal of Sociology 100(2): 381-421.

Campa, J.M., S. Kedia. 2002. Explaining the diversification discount, Journal of Finance 57(4):1731-62.

Christensen, C.M. and J.L. Bower. 1996. Customer power, strategic investment, and the failure of leading firms. Strategic Management Journal 17(3): 197-218.

Cyert, R.M. and J.G. March. 1963. A Behavioral Theory of the Firm. Prentice-Hall.

de Figueiredo, R.J.P., E. Rawley. 2011. Skill, luck and the multiproduct firm: Evidence from hedge funds. Management Science 57(11): 1963-78.

Desai, V. 2008. Constrained growth: How experience, legitimacy, and age influence risk taking in organizations. Organ. Sci., 19: 594-608.

Dunne, T., M.J. Roberts, and L. Samuelson. 1988. Patterns of firm entry and exit in U.S. manufacturing industries. The RAND Journal of Economics 19: 495-515.

Dunne, T., M.J. Roberts, and L. Samuelson. 1989. The growth and failure of U.S. manufacturing plants. The Quarterly Journal of Economis 104: 671-698.

Evans, D.S. 1987. The relationship between firm growth, size, and age: Estimates for 100 manufacturing industries. The Journal of Industrial Economics 35: 567-581.

Fung, W., D.A. Hsieh. 2001. The risk in hedge fund strategies: Theory and evidence from trend followers. Review of Financial Studies 14(2) 313-341.

Gavetti, G., D. Levinthal, and W. Ocasio. 2007. Neo-Carnegie: The Carnegie School's past, present, and reconstructing for the future. Organization Science 18(3) 523-536.

Gibbons, R. 1999. Taking Coase seriously. Admin. Sci. Quarterly, 44: 145-157.

Hannan, M.T. and J.H. Freeman. 1984. Structural inertia and organizational change Amer. Socio. Rev. 49: 149-64.

Hannan, M.T. 1998. "Rethinking age dependence in organizational mortality: Logical formalizations." Amer. J. of Sociol., 104(1): 126-164.

Hedge Fund Research. 2013. Global Hedge Fund Industry Report, First Quarter.

Iacus, S. M., G. King, and G. Porro. 2012. Causal Inference Without Balance Checking: Coarsened Exact Matching. Political Analysis 20(1): 1-24.

Jovanovic, B. 1982. Selection and the evolution of industry. Econometrica 50(3): 649-670.

Jensen, M.C., W.H. Meckling. 1976. Theory of the Firm: Managerial Behavior, Agency Costs and Ownership Structure. Journal of Financial Economics 3(4) 305-360.

Lang, L., and R. Stulz. 1994. Tobin's Q, diversification, and firm performance. J. Polit. Economy 102: 1248-1280.

Leonard-Barton, D.A. 1992. Core capabilities and core rigidities: A paradox in managing new product development. Strategic Management Journal 13: 111-126.

March, J.G. and H.A. Simon. 1958. Organizations. Blackwell Publishers: Cambridge, MA.

March, J.G. 1991. Exploration and exploitation in organizational learning. Org. Science 2(1): 71-87.

Miller, D., and M-J. Chen. 1994. Sources and consequences of competitive inertia: A study of the U.S. airline industry. Admin. Sci. Quarterly, 39: 1-23.

Nelson, R. and S. Winter. 1982. An Evolutionary Theory of Economic Change. Cambridge, MA: Harvard University Press. 
Nickerson, J. A. and B. S. Silverman (2003). Why firms want to organize efficiently and what keeps them from doing so. Administrative Science Quarterly 48: 433-65.

Ocasio, W. 1994. Political dynamics and the circulation of power: CEO succession in U.S. industrial corporations, 1960-1990. Administrative Science Quarterly 39(2): 285-312.

Pfeffer, J. 1981. Power in Organizations. Marshfield, MA: Pitman Publishing.

Phillips, D.J., C. Turco, and E. Zuckerman. 2013. Betrayal as market barrier: Identity-based limits to diversification among high-status corporate law firms. Amer. J. of Sociology 118(4) 1023-1054.

Pierce, L. 2012. Organizational structure and the limits of knowledge sharing: Incentive conflict and agency in car leasing. Management Science 58(6): 1106-1121.

Rawley, E. 2010. Diversification, coordination costs, and organizational rigidity: Evidence from microdata. Strategic Management Journal 31(8): 873-891.

Rosenbaum, P.R., D.B. Rubin. 1983. The central role of the propensity score in observational studies for causal effects. Biometrika 70(1) 41-55.

Schoar, A. 2002. Effects of corporate diversification on productivity. J. of Finance 57(6): 2379-2403.

Siggelkow, N. 2003. Why focus? A study of intra-industry focus effects. J. of Industrial Econ. 51(2) 121-150.

Smith, E.B. 2011. Identities as lenses: How organizational identity affects audiences' evaluation of organizational performance. Administrative Science Quarterly 56(1): 61-94.

Sørensen, J. and T.E. Stuart. 2000. Aging, obsolescence, and organizational innovation. Administrative Science Quarterly 45(1): 81-112.

Stinchombe, A. 1965. Social structure and organizations. Pp. 142-169 in Handbook of Organizations, ed. by J.G. March. McGraw-Hill.

Teece, D.J. 1982. Towards an economic theory of the multiproduct firm. J. Econ. Behavior and Org. 3(1) 39-63.

Shadab, HB. 2013. Hedge Fund Governance. Stanford Journal of Law, Business and Finance 19(1), forthcoming.

Silverman, B. 1999. Technological resources and the direction of corporate diversification: Toward an integration of the resource-based view and transaction cost economics. Management Science 45(8) 1109-1124.

Uzzi, B. 1996. The sources and consequences of embeddedness for the economic performance of organizations: The network effect. American Sociological Review 61: 674-698.

Zhou, Y. M. 2011. Synergy, coordination costs, and diversification choices. Strat. Management J. 32: 624-639.

Zuckerman, E. 1999. "The categorical imperative: Securities analysts and the illegitimacy discount." American Journal of Sociology 104: 1398-1438. 
Figure 1. Ex Ante Performance Distribution and Diversification Hurdles

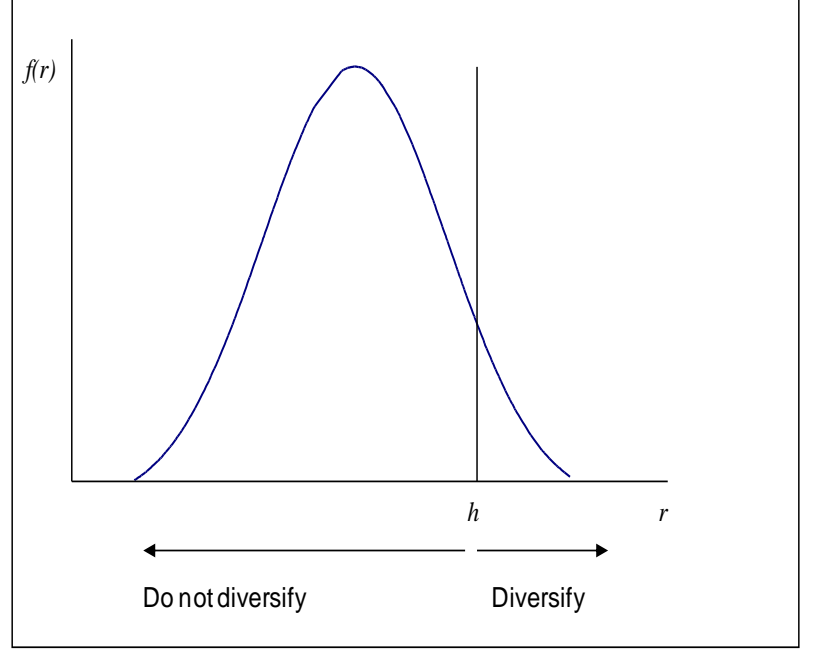

Figure 3. Political Frictions:

Ex Post Performance Distribution and Diversification By Age

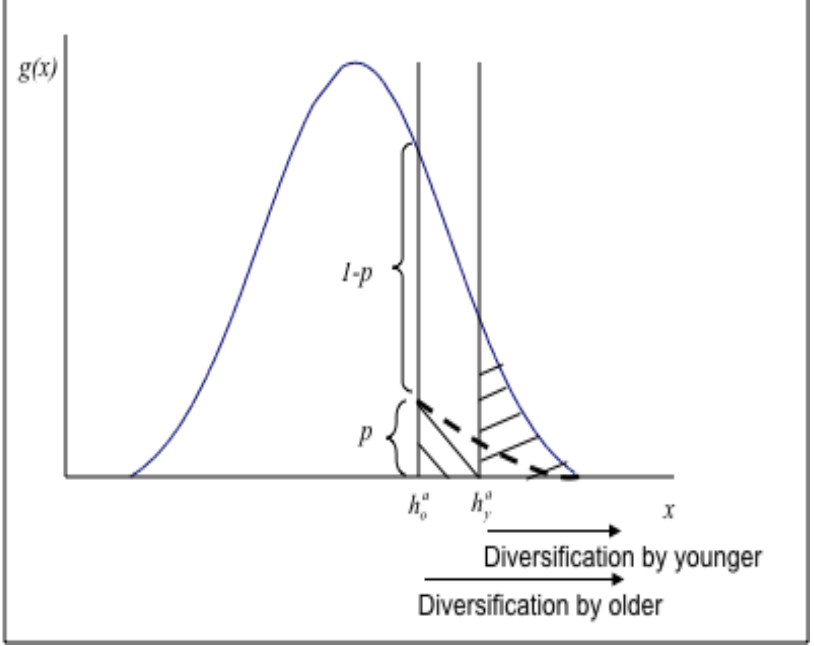

Figure 2. External Constraints:

x Ante Performance Distribution and Diversification By Age

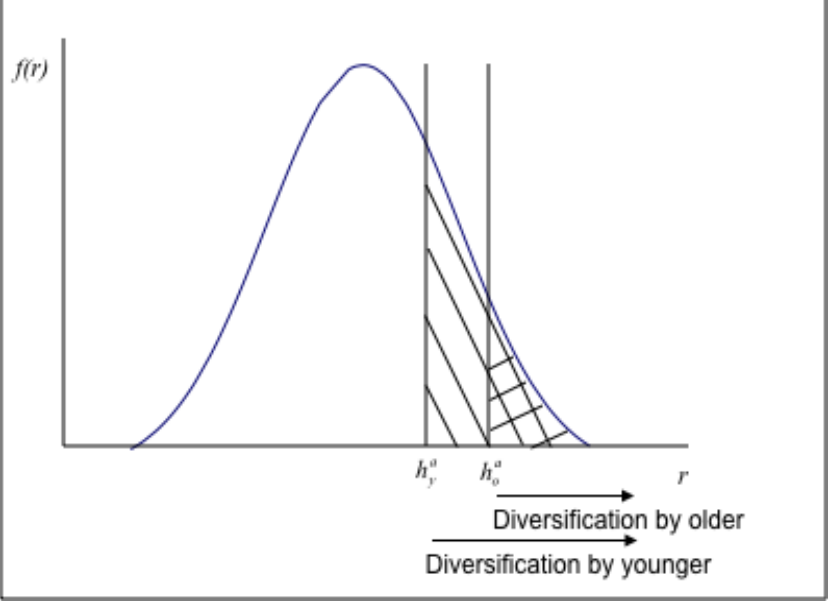

Figure 4. Implementation Costs: Ex Post Performance Distribution ar Diversification by Age

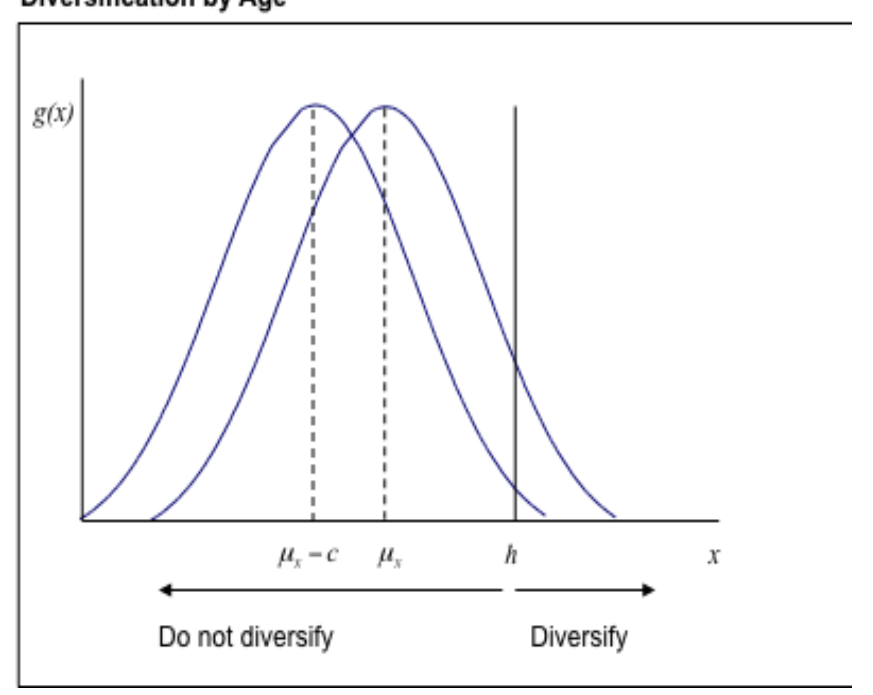


Table 1. Descriptive statistics and correlations for key variables

\begin{tabular}{rrrrr}
\hline $\mathrm{n}=165,379$ firm-months & Mean & St. Dev. & Min & Max \\
\hline Monthly diversification rate & 0.008 & 0.087 & 0 & 1 \\
Age (years) & 5.63 & 4.24 & 1 & 28 \\
24-month avg. cumulative abnormal returns (CAR) & 0.52 & 1.05 & -8.82 & 10.42 \\
8-factor excess returns & 0.44 & 3.62 & -11.58 & 13.84 \\
Information ratio & 0.18 & 0.91 & -2.43 & 3.01 \\
Standard deviation of firm performance & 2.81 & 2.02 & 0.02 & 12.53 \\
Funds managed by focal firm & 2.67 & 3.95 & 1 & 114 \\
Assets under management (AUM) \$B & 3.15 & 6.82 & 0.01 & 63.80 \\
Missing AUM (proportion) & 0.18 & 0.38 & 0 & 1 \\
Wait time between new fund launches (months) & 3.19 & 11.59 & 0 & 148 \\
Diversified entrant (proportion) & 0.14 & 0.34 & 0 & 1 \\
Year & 2001 & 3 & 1995 & 2005 \\
Headquarted in U.S. & 0.71 & 0.45 & 0 & 1 \\
Specialist funds (proportion) & 0.60 & 0.46 & 0 & 1 \\
Fund of funds (proportion) & 0.20 & 0.38 & 0 & 1 \\
Long/short funds (proportion) & 0.19 & 0.37 & 0 & 1 \\
\hline
\end{tabular}

Table 2. T-tests on covariate means before and after matching

\begin{tabular}{|c|c|c|c|}
\hline & $\begin{array}{l}\text { before matching } \\
\text { t-test on means } \\
\text { (young-old) }\end{array}$ & bins & $\begin{array}{l}\text { matched sample } \\
\mathrm{t} \text {-test on means } \\
\text { (young-old) }\end{array}$ \\
\hline Cumulative abnormal returns (CAR) & 4.5 & 10 & 0.4 \\
\hline Standard deviation of firm performance & 4.1 & 4 & -0.3 \\
\hline Funds managed by focal firm & -9.5 & 10 & -2.0 \\
\hline Assets under management (AUM) \$B & -9.7 & 10 & -1.4 \\
\hline Missing AUM (proportion) & -2.4 & 2 & 0.2 \\
\hline Wait time between new fund launches & -10.0 & 4 & -2.0 \\
\hline Year & -3.0 & 4 & 0.1 \\
\hline Headquarted in U.S. & -2.5 & 2 & -3.6 \\
\hline Fund of funds (proportion) & -0.4 & 2 & -0.2 \\
\hline Long/short funds (proportion) & -1.6 & 2 & -1.0 \\
\hline Management fee & -5.4 & 4 & 0.7 \\
\hline Incentive fee & -4.0 & 4 & 0.0 \\
\hline Strata & & 343 & \\
\hline Matched strata & & 78 & \\
\hline Young diversifiers & 540 & & 231 \\
\hline Old diversifiers & 512 & & 231 \\
\hline
\end{tabular}


Table 3. Scope and age

\begin{tabular}{|c|c|c|c|c|c|c|}
\hline & (1) & $(2)$ & (3) & (4) & (5) & (6) \\
\hline Specification & OLS & Dif-in-Dif & Logit & F.E. Logit & OLS & Exponential \\
\hline Sample & Full & Full & Full & Full & $\begin{array}{c}\text { 1st } \\
\text { diversification } \\
\text { event }\end{array}$ & $\begin{array}{c}\text { 1st } \\
\text { diversification } \\
\text { event }\end{array}$ \\
\hline Age (in years) & $\begin{array}{c}-0.0007 \\
(0.0001)\end{array}$ & $\begin{array}{c}-0.0024 \\
(0.0005)\end{array}$ & $\begin{array}{c}-0.126 * \\
(0.013)\end{array}$ & $\begin{array}{c}-0.325 * \\
(0.081)\end{array}$ & $\begin{array}{c}-0.0004 \\
(0.0000)\end{array}$ & $\begin{array}{c}-0.175 * \\
(0.016)\end{array}$ \\
\hline Controls & Yes & Yes & Yes & Yes & Yes & Yes \\
\hline firm fixed effects & No & Yes & No & Yes & No & No \\
\hline $\mathrm{N}$ (firm-months) & 165,379 & 165,379 & 165,379 & 52,955 & 164,885 & 164,885 \\
\hline Firms & 2,814 & 2,814 & 2,814 & 591 & 2,814 & 2,814 \\
\hline Diversification events & 1,052 & 1,052 & 1,052 & 1,052 & 558 & 558 \\
\hline
\end{tabular}

Controls inlcude: year fixed effects, number of funds (log), assets under management (log), cumulative abnormal returns, standard deviation of firm returns, waiting time between "events", fixed multiple funds. All time-varying covariates except age are lagged one month. Regressions without firm effects include categorical variables for headquarters location in the USA and whether the firm entered withinvestment strategy controls.

Robust standard errors are clustered at the firm level.

$* \rho<0.05 ;{ }^{+} p<0.10$; two-tailed tests.

Note: The economic magnitudes of the coefficient estimates in the grey ares are not comparable with the OLS/differences-in-differences estimates. Please see the text for a description of the economic interpretaton of the different coefficient estimates. 
Table 4. Age, scope and ex ante performance

\begin{tabular}{|c|c|c|c|c|c|c|c|}
\hline & & (1) & & (2) & (3) & (4) & (5) \\
\hline Specification & & Multinomial logit & & OLS & Dif-in-Dif & Mult. logit & OLS \\
\hline Sample & & Full sample & & Diversificatio & n events only & $\begin{array}{c}\text { Excluding } \\
\text { firms with } \\
\text { fund closures }\end{array}$ & $\begin{array}{c}1 s t \\
\text { diversificaiton } \\
\text { event only }\end{array}$ \\
\hline Dependent variable & $\begin{array}{l}\text { Below median } \\
\text { age at } \\
\text { diversification } \\
\text { date }\end{array}$ & $\begin{array}{l}\text { Above median } \\
\text { age at } \\
\text { diversification } \\
\text { date }\end{array}$ & $\begin{array}{c}\text { Difference } \\
\text { (above - } \\
\text { below) }\end{array}$ & $\begin{array}{l}\text { Above median } \\
\text { age at } \\
\text { diversification } \\
\text { date }\end{array}$ & $\begin{array}{c}\text { Above median } \\
\text { age at } \\
\text { diversification } \\
\text { date }\end{array}$ & $\begin{array}{c}\text { Difference } \\
\text { (above - } \\
\text { below) }\end{array}$ & $\begin{array}{l}\text { Above median } \\
\text { age at } \\
\text { diversification } \\
\text { date }\end{array}$ \\
\hline CAR & $\begin{array}{r}0.00055 * \\
(0.00012)\end{array}$ & $\begin{array}{r}-0.00007 \\
(0.00007)\end{array}$ & $\begin{array}{c}-0.00062 * \\
(0.00014)\end{array}$ & $\begin{array}{l}-0.078 * \\
(0.016)\end{array}$ & $\begin{array}{l}-0.071 * \\
(0.028)\end{array}$ & $\begin{array}{c}-0.00059 * \\
(0.00015)\end{array}$ & $\begin{array}{l}-0.080 * \\
(0.018)\end{array}$ \\
\hline $\begin{array}{r}\text { Controls } \\
\text { Firm fixed effects }\end{array}$ & & Yes & & Yes & Yes & Yes & Yes \\
\hline $\mathrm{N}$ (firm-months) & & 165,379 & & 1,052 & 1,052 & 103,517 & 558 \\
\hline Firms & & 2,814 & & 591 & 591 & 1,793 & 558 \\
\hline Diversification events & & 1,052 & & 1,052 & 1,052 & 575 & 558 \\
\hline
\end{tabular}

Controls inlcude: year fixed effects, number of funds (log), assets under management (log), cumulative abnormal returns, standard deviation of firm returns, waiting time between "events", funds. All time-varying covariates except age are lagged one month. Regressions without firm fixed effects include categorical variables for headquarters location in the USA and whether the firm entered with multiple investment strategy controls.

Marginal effects are reported for multinomial logit specifications and are not directly comparable to the OLS/Dif-in-dif estimates. Robust standard errors are clustered at the firm level.

${ }^{*} \rho<0.05{ }^{+} p<0.10$; two-tailed tests. 
Table 5. Age, scope and ex post performance

\begin{tabular}{|c|c|c|c|c|c|c|}
\hline OLS regressions & (1) & $(2)$ & (3) & (4) & (5) & (6) \\
\hline Sample & Full & Full & Matched & Matched & $\begin{array}{l}\text { Matched new } \\
\text { funds only }\end{array}$ & $\begin{array}{l}\text { Matched } x \text { - } \\
\text { new funds }\end{array}$ \\
\hline Unit of analysis & Firm-month & Firm-month & Firm-month & Firm-month & Fund-month & Fund-month \\
\hline Dependent variable & Excess Returns & Info Ratio & Excess Returns & Info Ratio & Info Ratio & Info Ratio \\
\hline \multirow[t]{2}{*}{ Age (in years) } & $-0.030 *$ & $-0.013 *$ & $-0.015 *$ & $-0.010 *$ & $-0.004 *$ & $-0.007 *$ \\
\hline & $(0.003)$ & $(0.001)$ & $(0.006)$ & $(0.004)$ & $(0.002)$ & $(0.002)$ \\
\hline Diversified & $\begin{array}{r}0.030 \\
(0.033)\end{array}$ & $\begin{array}{r}0.090 * \\
(0.012)\end{array}$ & & & & \\
\hline \multirow[t]{2}{*}{ Diversified x Age } & -0.020 & $0.092 *$ & & & & \\
\hline & (0.013) & $(0.007)$ & & & & \\
\hline Controls & Yes & Yes & Yes & Yes & Yes & Yes \\
\hline $\mathrm{N}$ & 165,379 & 165,379 & 20,086 & 20,086 & 26,742 & 47,508 \\
\hline Firms & 2,814 & 2,814 & 358 & 358 & 358 & 358 \\
\hline Diversification events & 1,052 & 1,052 & 462 & 462 & 462 & 462 \\
\hline
\end{tabular}

Controls inlcude: year fixed effects, number of funds (log), assets under management (log), cumulative abnormal returns, standard deviation of firm returns, waiting time between "events", investment strategy controls.

Regressions without firm fixed effects include categorical variables for headquarters location in the USA and whether the firm entered with multiple funds. All time-varying covariates except age are lagged one month.

Robust standard errors clustered at the firm level.

${ }^{*} \rho<0.05 ;{ }^{+} p<0.10$; two-tailed tests.

Note: In the matched sample, treatment group observations (i.e., old diversifiers) are matched to control group observations (i.e., young diversifiers) at the time of diversification. There are 231 diversification events where the firm was older than the median age and 231 diversification events where the firm was younger than the median age. 67 firms have multiple diversification spells in the matched sample as each diversification event is treated as a unique observation for the purposes of matching. 
Table 6. Exploration versus exploitation

\begin{tabular}{ccccccc}
\hline & $(1)$ & $(2)$ & $(3)$ & $(4)$ & $(5)$ & $(6)$ \\
\hline Specification & \multicolumn{1}{c}{ Dif-in-Dif } & Multinomial logit & & OLS & \\
\hline Sample & Explore & Exploit & Explore & Exploit & $\begin{array}{c}\text { Explore } \\
\text { (matched) }\end{array}$ & $\begin{array}{c}\text { Exploit } \\
\text { (matched) }\end{array}$ \\
\hline
\end{tabular}

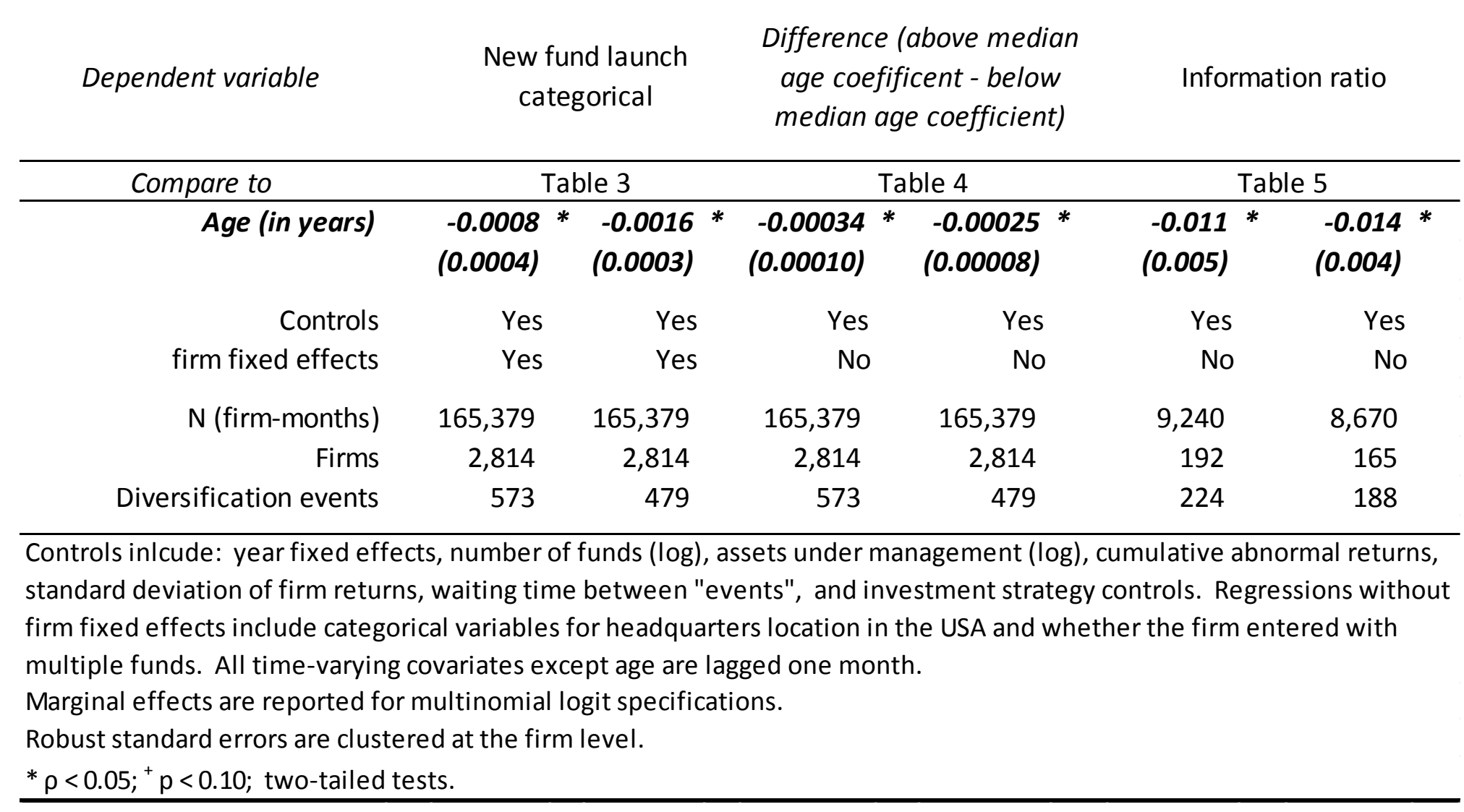

